\title{
Four left renal arteries - a rare variant of kidney arterial supply
}

\author{
G. Wróbel ${ }^{1}$, M. Spałek ${ }^{1}{ }^{2}$, J. Kuchinka ${ }^{3}$, T. Kuder ${ }^{1}$ \\ ${ }^{1}$ Department of Anatomy, Institute of Medical Sciences, Faculty of Medicine and Health Sciences, \\ Jan Kochanowski University, Kielce, Poland \\ 2Department of Medical Imaging, Holy Cross Cancer Centre, Kielce, Poland \\ ${ }^{3}$ Department of Comparative Anatomy of Vertebrates, Institute of Biology, \\ Faculty of Mathematics and Natural Sciences, Jan Kochanowski University, Kielce, Poland
}

Received: 6 March 2018; Accepted: 5 April 2018]

We describe the arterial supply of a human kidney harvested post-mortem from a 75-year-old female volunteer body donor. The kidney was analysed with contrast-enhanced computed tomography (CT), and corrosion casting was used to reveal the kidney's angio-architecture. In the left kidney, we observed four renal arteries, each originating directly from the abdominal aorta. Three renal arteries, including the main renal artery, coursed through the renal hilum, and the fourth renal artery reached the lower kidney pole. The supply areas of each of the four renal arteries were analysed with a three-dimensional reconstruction of CT images and with corrosion casting. There were no clear boundaries between the areas supplied by the four renal arteries because their branches overlapped in most kidney segments. (Folia Morphol 2019; 78, 1: 208-213)

Key words: renal artery, accessory, supernumerary, anatomical variation, corrosion casting, computed tomography

\section{INTRODUCTION}

The anatomy of the human kidney arterial supply can vary substantially between people $[3,18$, $22,32]$, and this variation is an interesting research subject. Awareness of the many anatomical variants of the renal vascular system is important in the diagnosis of kidney diseases, and it helps understand why some patients have unusual clinical presentations. Knowing the anatomy of the renal vessels is particularly important in kidney transplantation, in which an accurate radiological evaluation of these vessels is essential to plan surgery $[5,18,28]$.

Based on data from previous studies, the kidney is supplied by a single artery in $75 \%$ of cases ( $70 \%$ to $85 \%$ ), more often the right kidney. In the remaining $25 \%$ of cases ( $20 \%$ to $30 \%$ ), at least
2 arteries supply 1 kidney. In $\sim 20 \%$ of cases ( $14 \%$ to $23 \%$ ), the kidney is supplied by 2 renal arteries originating from the abdominal aorta; in $\sim 2.5 \%$ of cases ( $1 \%$ to $4 \%$ ), by 3 renal arteries; and in only $<1 \%$ of cases, by 4 renal arteries $[5,8,18,29]$. The occurrence of additional renal arteries depends on the sex and race [23].

\section{CASE REPORT}

We examined a human kidney harvested post-mortem from a 75-year-old female volunteer body donor (Fig. 1). The kidney was fixed in a preservative medium $(10 \%$ formalin $+40 \%$ alcohol $+90 \%$ glycerol) and then analysed with contrast-enhanced computed tomography (CT). Special radiographic procedures using contrast media are used in certain cases to delineate internal structures. 


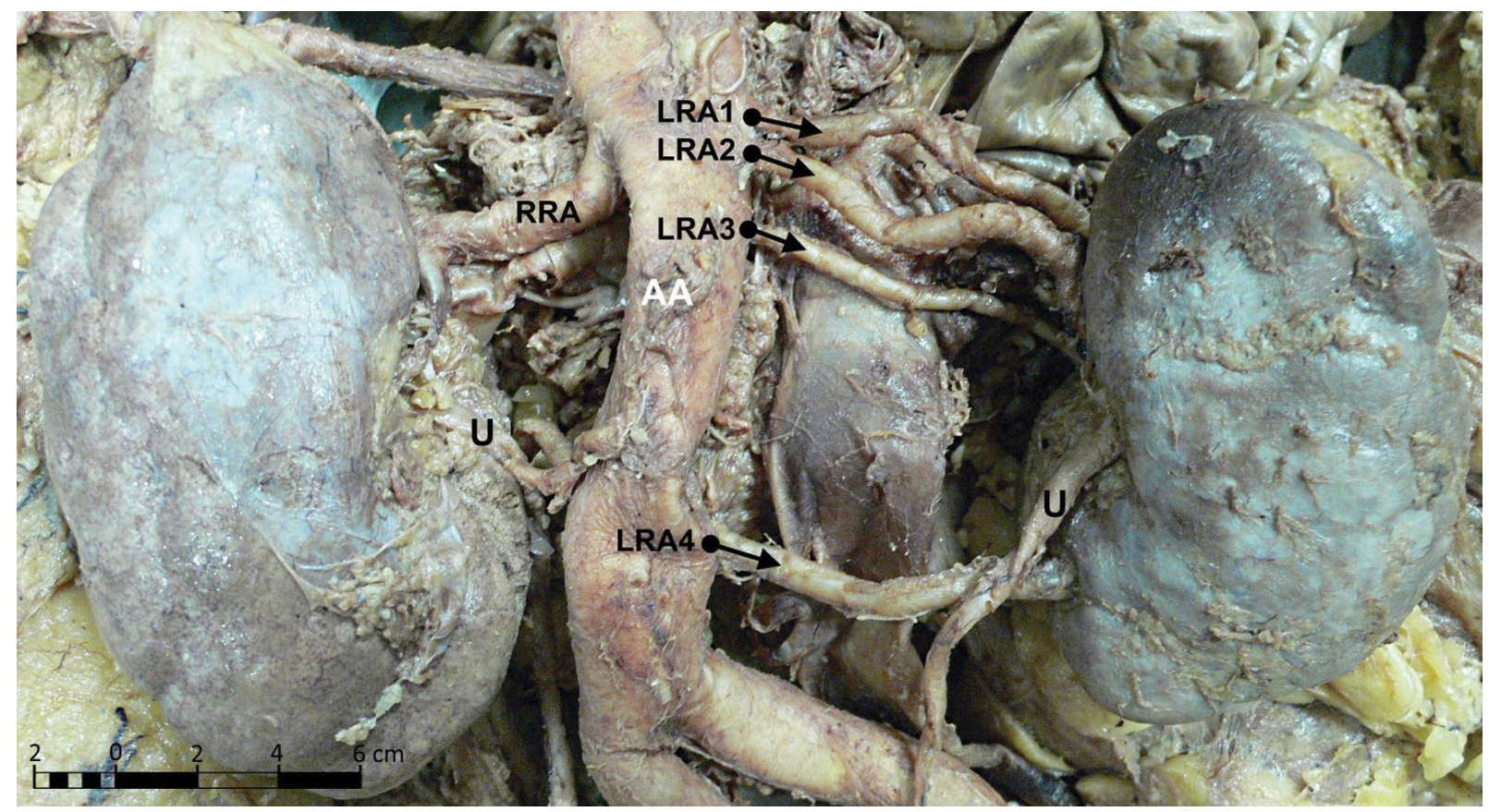

Figure 1. Renal artery system after the post-mortem examination; AA — abdominal aorta; LRA1-4 — left renal arteries; RRA — right renal artery; $\mathrm{U}$ - ureter.

A contrast agent was used in the study - OMNIPAQUE 350; contains $755 \mathrm{mg}$ of iohexol equivalent to $350 \mathrm{mg}$ of organic iodine per $\mathrm{mL}$ - each millilitre of iohexol solution contains $1.21 \mathrm{mg}$ tromethamine and $0.1 \mathrm{mg}$ edetate calcium disodium with the $\mathrm{pH}$ adjusted between 6.8 and 7.7 with hydrochloric acid or sodium hydroxide. Osmolality from 2.2 to 3 times that of plasma ( $285 \mathrm{mOsm} / \mathrm{kg}$ water) or cerebrospinal fluid (301 $\mathrm{mOsm} / \mathrm{kg}$ water), solution is hypertonic in the conditions of use). We injected about $10 \mathrm{~mL}$ of $3 \%$ solution of the contrast agent into each of the renal arteries, and then the arteries were ligated. The CT examination was performed using SOMATOM Definition AS (Siemens) and analysed with SYNGO Multi-Modality CT Workstation (Siemens). We used corrosion casting to visualise the blood vessels. We filled the blood vessels with latex (LBS 3060) and used 10\% $\mathrm{KOH}+5 \% \mathrm{H}_{2} \mathrm{O}_{2}$ for soft tissue digestion at about $38^{\circ} \mathrm{C}$ for a week. Based on CT images, we obtained a three-dimensional reconstruction of the renal arterial supply system (Fig. 2), and the corrosion cast showed the angio-architectonics of the kidney (Fig. 3).

We examined both the courses and supply areas of the 4 renal arteries originating directly from the abdominal aorta and supplying individual kidney segments. In addition, for each renal artery, we measured both the distance from its origin in the abdominal aorta to the aortic bifurcation and its external diameter at the origin (Table 1). We found that 3 renal arteries coursed through the renal hilum. The artery with the largest diameter $(5.1 \mathrm{~mm})$ was considered the main renal artery (Fig. 1, LRA2). The other 2 arteries in the renal hilum, i.e., LRA1 ( $4 \mathrm{~mm}$ in diameter) and LRA3 (4.4 $\mathrm{mm}$ in diameter), were considered accessory renal arteries (Fig. 1). The 3 renal arteries that coursed through the renal hilum branched off directly from the aorta at a distance from the aortic bifurcation of 105 $\mathrm{mm}$ (LRA1), $100 \mathrm{~mm}$ (LRA2), and $90 \mathrm{~mm}$ (LRA3). The fourth renal artery branched off from the aorta $35 \mathrm{~mm}$ from the aortic bifurcation, i.e., below the other renal arteries (Fig. 1, Table 1). One of the renal arteries (LRA1) supplied mainly the posterior renal segment and, to a lesser extent, the inferior renal segment. The main renal artery (LRA2) supplied a substantial part of the kidney parenchyma, i.e., the apical and anterosuperior segments, and part of the anteroinferior segment. Another renal artery (LRA3) supplied the posterior segment and part of the inferior segment, which was the smallest supply area of all 4 renal arteries. The renal artery that joined the kidney near its lower pole (LRA4) supplied mainly the inferior segment and part of the anteroinferior segment, additionally an unusual course of the left ureter 

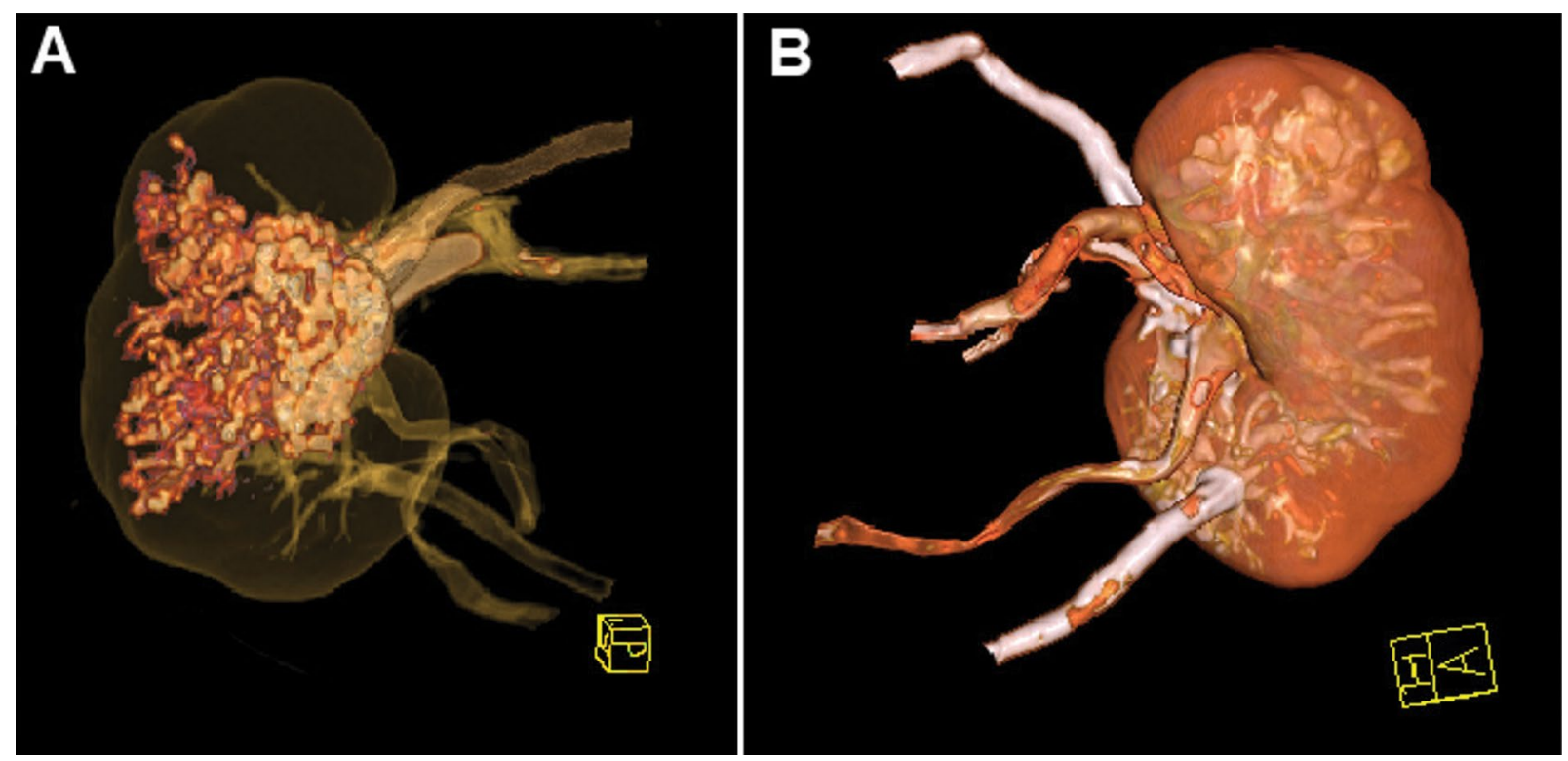

Figure 2. Computed tomography reconstruction of the kidney; A. Image after injecting the first renal artery; B. Image after injecting all renal arteries.

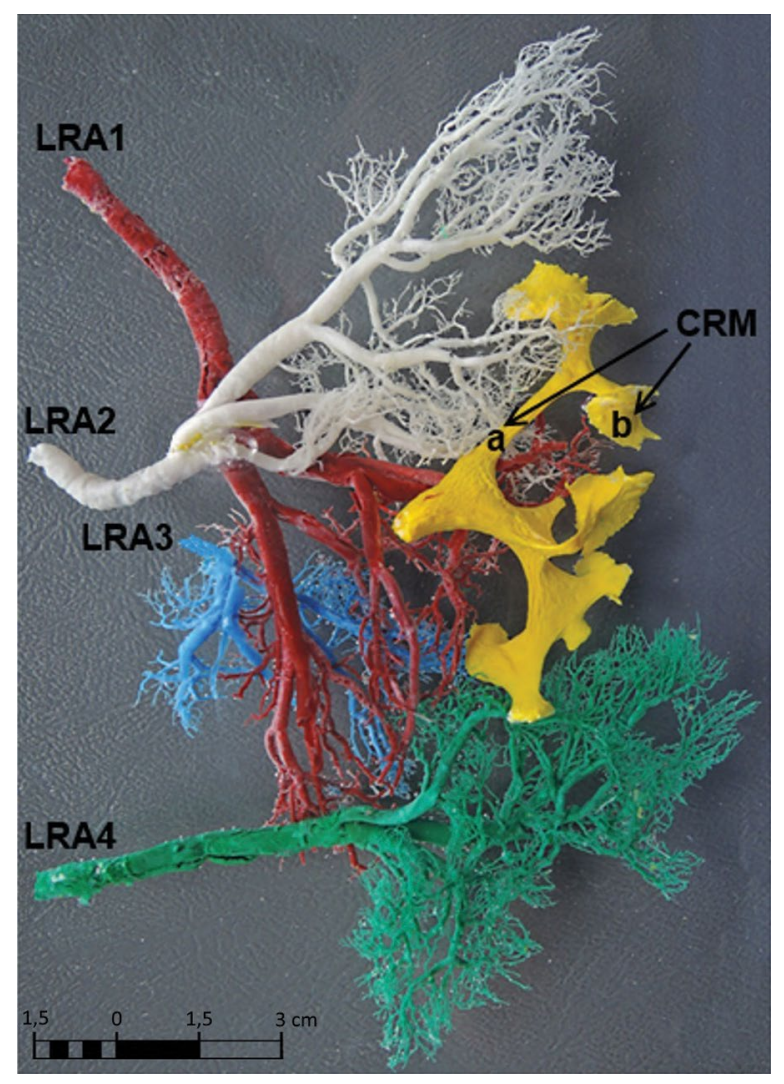

Figure 3. Corrosion casting of the kidney; LRA1-4 - left renal arteries; CRM — renal calyces; $a$ - major; $b$ - minor.

was observed - it crosses anteriorly LRA4 (Fig. 1). The CT images and the corrosion cast both showed that there were no clear borders between the blood supply areas in the kidney, because the arteries were interconnected and had overlapping branches - particularly the interlobular arteries. Only the apical renal segment received blood supply from a single artery (the "main" renal artery). Moreover, a substantial part of the inferior renal segment received blood supply from the lowest additional renal artery (LRA4, Fig. 2).

\section{DISCUSSION}

Typically, single renal arteries branch off from both sides of the aorta and then bifurcate, near the renal hilum, into the anterior and posterior branches, which divide further into segmental arteries supplying different renal segments. It is common to see more than 1 renal artery supplying a single kidney, and previous investigators described cases with renal arteries of varying numbers and courses $[18,22,26-29]$. The frequency of multiple renal arteries is determined by the feature of population. For example, in Caucasian and African populations a high incidence of multiple renal arteries is observed (30-40\%), compared to Indian population $(13.5 \%)[22,27]$. The frequency of presence of multiple renal arteries varies widely with ethnicity. According to Gulas et al. [7], range of the frequency of multiple renal arteries depending on ethnicity is between 4\% (Malaysians) and $61.5 \%$ (Indians). In Polish population, the variability of multiple renal arteries seems to be between $11.2 \%$ and $38.3 \%$ 
Table 1. Morphological parameters of the renal arteries. Additional renal arteries were grouped into the extra renal artery by a previous classification $[17,22]$

\begin{tabular}{|c|c|c|c|c|}
\hline Variables & LRA1 & LRA2 & LRA3 & LRA4 \\
\hline Classification & Extra renal artery: hilar & Main: hilar & Extra renal artery: hilar & Extra renal artery: polar \\
\hline External diameter at origin [mm] & 4.0 & 5.1 & 2.7 & 4.5 \\
\hline $\begin{array}{l}\text { Distance from the bifurcation of the } \\
\text { abdominal aorta [mm] }\end{array}$ & 105 & 100 & 90 & 35 \\
\hline Renal segment supplied & Posterior, lower & Apical, upper, middle & Posterior, lower & Middle, lower \\
\hline
\end{tabular}

LRA1-4 - left renal arteries

$[7,25]$. The classification of additional renal arteries is ambiguous, and different investigators use different terms to describe additional renal arteries, which hinders research on the subject. For example, Merklin and Michels [14] distinguish "supernumerary" arteries, whereas Graves [6] describes each additional renal artery arising from the abdominal aorta as "accessory" and those arteries not arising from the aorta as "aberrant". Herein, we used the classification of additional renal arteries put forward by Satyapal et al. [23] and Özkan et al. [18]. In this classification, additional renal arteries fall into two categories: (1) early division arteries, i.e., those branching off from the main renal arteries into segmental branches more proximally than the renal hilum; and (2) extra renal arteries, which are further classified as hilar (accessory) arteries and polar (aberrant) arteries. Hilar arteries, along with the main renal artery, enter the kidney through the renal hilum, whereas the aberrant arteries run directly towards the renal capsule and do not enter the renal hilum. Based on these criteria, the LRA4 artery described herein can be classified as an aberrant artery. Kidneys supplied by more than one artery can have other anatomical variations, such as more than one vein or ureter [24]. We, however, did not find such anatomical variants in the presented case. The anatomical variations of renal arteries are much more common than the variations of renal veins [11]. According to Bordei et al. [2], the former occur 8 times as often as the latter. Rossi et al. [21] put forward that the common occurrence of vascular changes in the kidneys may be due to the disturbances of kidney migration early in the development of blood vessels, which may lead to the formation of additional renal arteries. Moreover, Satyapal et al. [23] propose that an abnormal spatial arrangement of the kidney promotes the development of abnormal blood vessels.
Our description of four renal arteries supplying one kidney is very rare among the existing reports on the variations of renal arterial supply; it is not, however, the only such description $[5,19,20,25$, 29]. Previous investigators reported many interesting variants of the renal arterial supply. Kinnunen et al. [12] described one of the most interesting cases, in which ten arteries supplied one kidney. Miclaus and Matusz [15] described a 58-year-old man with 4 renal arteries supplying each kidney. Rossi et al. [21] described a 23-year-old male living donor candidate with 4 arteries supplying the left kidney and 3 arteries supplying the right kidney. Koplay et al. [13] presented a case of a 36-year-old patient with 7 renal arteries: 3 arteries on the right and 2 arteries on the left branched off from the abdominal aorta; 1 artery on the left branched off from the lower mesenteric artery; and 1 artery on the right, from the common iliac artery. Orlando et al. [17] described a kidney transplant recipient with 6 arteries - the first instance of successful transplantation of a kidney with more than 4 arteries [1]. Mishra et al. [16] found 5 renal arteries in an 18-year-old woman undergoing CT (3 right and 2 left arteries). In a post-mortem examination of a 61-year-old man, Jeon et al. [10] observed 3 right and 2 left renal arteries with asymmetric origin.

Other studies support these observations [5]. Other authors $[19,20]$, however, indicate that renal arteries show greater variability on the left side compared with the right side. Saldarriaga et al. [22] and Satyapal et al. [23] found additional renal arteries more often on the left than on the right side. In our case, the additional renal vessels occurred on the left side as well. In the study by Jeon et al. [10], the distance from the origin of additional renal arteries to the aortic bifurcation ranged between 30 and $118 \mathrm{~mm}$, and the external diameter of these arteries at their origin ranged from 3 to 7 
$\mathrm{mm}$. In the study by Mishra et al. [16], this diameter ranged between 2.5 and $4.3 \mathrm{~mm}$. Additional inferior aberrant renal arteries are rare. Vilhova et al. [30] found that superior aberrant renal arteries occurred more often than did inferior aberrant renal arteries ( $22 \%$ vs. $4.4 \%$ ), and Budhiraja et al. [4] reported similar figures. Other studies, however, reported a more frequent occurrence of inferior aberrant renal arteries compared with that of superior aberrant renal arteries [9, 31]. Aberrant renal arteries usually have smaller diameters than do the main renal arteries entering the kidney through the renal hilum [26]. In some people, aberrant renal arteries may cause ureteral obstruction leading to hydronephrosis, which is an important clinical problem [26].

\section{CONCLUSIONS}

In conclusion, we described a rare occurrence of a kidney supplied by 4 arteries. This is an additional source of information that can have clinical implications. Clinically, one should take into account that renal arteries have many anatomical variants, which is important in kidney disease diagnosis, renal vessel surgery, and kidney transplantation.

\section{REFERENCES}

1. Bachul PJ, Osuch C, Chang ES, et al. Crossing anatomic barriers-transplantation of a kidney with 5 arteries, duplication of the pyelocalyceal system, and double ureter. Cell Transplant. 2017; 26(10): 1669-1672, doi: $10.1177 / 0963689717722169$, indexed in $\mathrm{Pu}$ bmed: 28933184.

2. Bordei P, Sapte E, lliescu D. Double renal arteries originating from the aorta. Surg Radiol Anat. 2004; 26(6): 474-479, doi: 10.1007/s00276-004-0272-9, indexed in Pubmed: 15378279.

3. Budhiraja V, Rastogi R, Asthana AK. Variant origin of superior polar artery and unusual hilar branching pattern of renal artery with clinical correlation. Folia Morphol. 2011; 70(1): 24-28, indexed in Pubmed: 21604249.

4. Budhiraja V, Rastogi R, ain V, et al. Anatomical variations of renal artery and its clinical correlations: a cadaveric study from central India. J Morphol Sci. 2013; 30(4): 228-233.

5. Dogra A, Chauhan RS, Sharma S, et al. Variations of renal arteries on 64 slice Multidetector Computed Tomography. J Anat Soc India. 2017; 66(1): 20-25, doi: 10.1016/j. jasi.2017.05.001.

6. Graves FT. The aberrant renal artery. J Anat. 1956; 90(4): 553-558, indexed in Pubmed: 13366870.

7. Gulas E, Wysiadecki G, Szymański J, et al. Morphological and clinical aspects of the occurrence of accessory (multiple) renal arteries. Arch Med Sci. 2018; 14(2): 442-453, doi: 10.5114/aoms.2015.55203, indexed in Pubmed: 29593819.
8. Hapugoda S, Knipe H. Accessory renal artery. Radiopedia. https://radiopaedia.org/articles/accessory-renal-artery (January 3rd 2018).

9. Hassan SS, El-Shaarawy EA, Johnson JC, et al. Incidence of variations in human cadaveric renal vessels. Folia Morphol. 2017; 76(3): 394-407, doi: 10.5603/FM.a2017.0020, indexed in Pubmed: 28281721.

10. Jeon YJ, Lee JN, Yoon SP. Bilateral asymmetrical multiple renal arteries associated with the left testicular artery. Folia Morphol. 2014; 73(4): 510-513, doi: 10.5603/ FM.2014.0078, indexed in Pubmed: 25448913.

11. Kadir S. Kidneys. In: Kadir S (ed.), Atlas of normal and variant angiographic anatomy. Philadelphia: W.B. Saunders Company. 1991: 387-429.

12. Kinnunen J, Tötterman S, Tervahartiala P. Ten renal arteries. Eur J Radiol. 1985; 5(4): 300-301, indexed in Pubmed: 4085494.

13. Koplay $M$, Onbas $O$, Alper F, et al. Multiple renal arteries: variations demonstrated by multidetector computed tomography angiography. Med Princ Pract. 2010; 19(5): 412-414, doi: 10.1159/000316384, indexed in Pubmed: 20639669.

14. Merklin RJ, Michels NA. The variant renal and suprarenal blood supply with data on the inferior phrenic, ureteral and gonadal arteries: a statistical analysis based on 185 dissections and review of the literature. J Int Coll Surg. 1958; 29(1 Pt 1): 41-76, indexed in Pubmed: 13502578.

15. Miclaus GD, Matusz P. Bilateral quadruple renal arteries. Clin Anat. 2012; 25(8): 973-976, doi: 10.1002/ca.22083, indexed in Pubmed: 22508263.

16. Mishra A, Sharma PK, Manik $P$, et al. Bilateral multiple renal arteries: A case report. OA Anatomy. 2014; 2(3): 22.

17. Orlando G, Gravante G, D'Angelo $M$, et al. A renal graft with six arteries and double pelvis. Transpl Int. 2008; 21(6): 609-611, doi: 10.1111/j.1432-2277.2008.00659.x, indexed in Pubmed: 18298589.

18. Ozkan U, Oğuzkurt L, Tercan F, et al. Renal artery origins and variations: angiographic evaluation of 855 consecutive patients. Diagn Interv Radiol. 2006; 12(4): 183-186, indexed in Pubmed: 17160802.

19. Patil UD, Ragavan A, Nadaraj T, et al. Helical CT angiography in evaluation of live kidney donors. Nephrol Dial Transplant. 2001; 16(9): 1900-1904, indexed in Pubmed: 11522876.

20. Pollak R, Prusak BF, Mozes MF. Anatomic abnormalities of cadaver kidneys procured for purposes of transplantation. Am Surg. 1986; 52(5): 233-235, indexed in Pubmed: 3518559.

21. Rossi UG, Romano $M$, Ferro $C$. Seven renal arteries. Clin Anat. 2006; 19(7): 632-633, doi: 10.1002/ca.20264, indexed in Pubmed: 16372339.

22. Saldarriaga B, Pérez AF, Ballesteros LE. A direct anatomical study of additional renal arteries in a Colombian mestizo population. Folia Morphol. 2008; 67(2): 129-134, indexed in Pubmed: 18521812.

23. Satyapal KS, Haffejee AA, Singh B, et al. Additional renal arteries: incidence and morphometry. Surg Radiol Anat. 2001; 23(1): 33-38, indexed in Pubmed: 11370140.

24. Soares T, Ferraz J, Dartibale C, et al. Variations in human renal arteries. Acta Scientiarum Biological Sciences. 2013; 35(2): 277-282, doi: 10.4025/actascibiolsci.v35i2.11178.

25. Sośnik H, Sośnik K. Investigations on renal vascularisation pathology in the Polish population. 1. Incidence 
of multiple kidney arteries. Folia Morphol. 2017; 76(2): 226-231, doi: 10.5603/FM.a2016.0073, indexed in Pubmed: 28026854.

26. Stanca VD, Precup D, Popescu A, et al. Anatomic variants of origin, number and course of the renal arteries. an anatomical study. Medical Connections. 2013; 4(32): 19-23.

27. Staśkiewicz G, Jajko K, Torres K, et al. Supernumerary renal vessels: analysis of frequency and configuration in 996 computed tomography studies. Folia Morphol. 2016; 75(2): 245-250, doi: 10.5603/FM.a2015.0085, indexed in Pubmed: 26383508.

28. Tarzamni MK, Nezami N, Rashid RJ, et al. Anatomical differences in the right and left renal arterial patterns. Folia Morphol. 2008; 67(2): 104-110, indexed in Pubmed: 18521808 .
29. Türkvatan A, Ozdemir M, Cumhur T, et al. Multidetector $\mathrm{CT}$ angiography of renal vasculature: normal anatomy and variants. Eur Radiol. 2009; 19(1): 236-244, doi: 10.1007/ s00330-008-1126-3, indexed in Pubmed: 18665365.

30. Vilhova I, Kryvko YY, Maciejewski R. The radioanatomical research of plural renal arteries. Folia Morphol. 2001; 60(4): 337-341, indexed in Pubmed: 11770346.

31. Weld KJ, Bhayani SB, Belani J, et al. Extrarenal vascular anatomy of kidney: assessment of variations and their relevance to partial nephrectomy. Urology. 2005; 66(5): 985-989, doi: 10.1016/j.urology.2005.05.023, indexed in Pubmed: 16286108.

32. Wozniak WT. Origin of the renal arteries from sides of aorta. Folia Morphol. 2000; 58(4): 259-261, indexed in Pubmed: 11000882. 